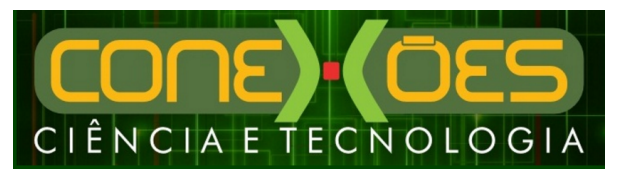

\title{
O ENSINO NA PERSPECTIVA DA GRAMÁTICA CONTEXTUALIZADA: ANÁLISE DAS ORIENTAÇÕES CURRICULARES DO ESTADO DO CEARÁ
}

\author{
TÁLYSON MARQUES DA SILVA ${ }^{1}$ \\ ${ }^{1}$ Universidade Estadual do Ceará - UECE \\ $<$ talysonmarquesdasilva@gmail.com>
}

DOI: 10.21439/conexoes.v12i2.1444

\begin{abstract}
Resumo. O ensino de Língua Portuguesa tem sido alvo de inúmeras discussões no âmbito acadêmico/escolar ao longo dos anos, principalmente no que tange às discussões sobre o estudo da gramática, normalmente desenvolvido de modo mecanizado, automatizado e normativo. Diante disso, novas estratégias metodológicas são apresentadas aos docentes de língua materna. Defende-se - nesta pesquisa as eficácias do ensino de gramática que considera não a estrutura da língua por si, mas sim a sua efetiva e eficiente realização nos sistemas significantes (textos) produzidos nas mais diversas situações sociointeracionais das quais participam os sujeitos. Nessa perspectiva, o objetivo deste trabalho é analisar as informações presentes nas Orientações Curriculares do Estado do Ceará acerca da gramática contextualizada. Ancorou-se, teoricamente, nos pressupostos defendidos por Antunes (2014), que explora o papel da gramática no ensino de língua, defendendo-a na perspectiva contextualizada, entre outros autores. Em termos metodológicos, essa investigação foi realizada em duas etapas: 1) Levantamento teórico, caracterizada como bibliográfica, segundo Marconi e Lakatos (2003); 2) Análise do documento supracitado, o que aproxima esse trabalho de uma pesquisa documental. Os resultados mostraram que o documento faz alusão ao ensino contextualizado da gramática, afirmando, inclusive, que o ensino de Língua Portuguesa, no Ensino Médio, deve contemplar outras dimensões da língua, além da muito explorada dimensão metalinguística.
\end{abstract}

Palavras-chaves: Ensino de Língua Portuguesa. Gramática Contextualizada. Legislação.

\begin{abstract}
The Portuguese language teaching has been the object of several discussions in the academic and school world along of the years, especially about the study of grammar that is usually developed mechanized, automated and normative way. Thereby, new methodological strategies are presented to the teachers of native language for the treatment of the main instrument of interaction between individuals that is in line with the objectives inherent to their daily communicative practices. It is argued in this study the efficacy of grammar teaching that does not consider the structure of the language itself, but its effective and efficient performance in significant systems (texts) produced in several social-interaction situations which involved subjects. In this perspective, this study aims to evaluate the Portuguese language teaching at the high school of Basic Education, analyzing the contributions made from the perspective of the grammar in context and by rules within the classroom. It is anchored in theorical assumptions defended by Antunes (2014), which explores the role of grammar in language teaching, defending it in contextualized perspective, and the considerations of other authors. In methodological terms, this research was carried out in two stages: 1) Theoretical survey, characterized as bibliographical, according to Marconi e Lakatos (2003); 2) Analysis of the aforementioned document, which brings this work closer to documentary research. The results showed that the document alludes to the contextualized teaching of grammar, affirming that Portuguese language teaching in secondary education should include other dimensions of the language, as well as the much explored metalinguistic dimension.
\end{abstract}

Keywords: Teaching Portuguese Language. Contextualized Grammar. Legislation. 


\section{INTRODUÇÃO}

No Brasil, o ensino de Língua Portuguesa tem se desenvolvido ao longo de muitos anos sob um viés tradicional, que preserva muito mais a memorização dos conteúdos didáticos do que mesmo a efetivação da aprendizagem desses e de outros mecanismos que também dão sentido às praticas sociais comunicativas.

Tal concepção didático-metodológica de ensino prejudica o desenvolvimento cognitivo dos alunos, aos quais devemos ofertar conhecimentos e saberes mais articulados, como, por exemplo: saber como se posicionar frente a situações de interação que exigem maior grau de formalidade ou informalidade da língua; reconhecer e valorizar, igualmente, as variações linguísticas; saber identificar, no texto, os elementos verbais e não verbais que estão a serviço do cumprimento de um propósito comunicativo, dentre outros.

Inserido nesse contexto tradicionalista, o trabalho com a língua materna tem se caracterizado como mecanizado, automatizado e normativo (WAAL, 2009), sendo isto justificado por um fator histórico, pois, com a defesa da concepção de gramática como instrumento de dominação através da prescrição de normas, o ensino tem confirmado conservadoras estratégias de doutrinação e alienação, reforçando o mito de que a "língua certa" é a aquela preceituada pela norma-padrão, e tudo o que não atender ao que ela determina é taxado de "errado" e "feio". Essas compreensões errôneas do que, de fato, é língua confundem até os ditos "preparados academicamente" para lecionar em sala de aula.

Dessa forma, as concepções de língua(gem) e gramática têm sido tratadas como equivalentes, gerando um equívoco que, inevitavelmente, repercute na prática da sala de aula e reforça o conceito de que gramática é a própria língua e que estudar língua é estudar tão somente sua gramática. São essas questões que permeiam os espaços escolares e configuram o ensino de Língua Portuguesa como normativo, apesar de diversos estudos científicos já desmistificarem questões como essas, como bem nos lembram inúmeras contribuições da linguística moderna.

Com essa perspectiva conservadora, as aulas se restringem a atividades puramente estruturais as quais se limitam à frase descontextualizada, descartando todos os aspectos pragmático-discursivos a serem levados em consideração quando da exploração dos potenciais recursos expressivos disponibilizados pela língua.

Nesse sentido, o que se tem constatado, no que tange ao trabalho com a língua materna, é a insistência, preservação e propagação de um ensino prescritivo e estigmatizante, que não se dispõe, muitas vezes, a aceitar novas propostas que visam a um ensino mais crítico e reflexivo sobre o sistema linguístico e seus fenômenos multifacetados.

Diante desse quadro representativo, no qual se encontra boa parte das instituições escolares, cabe-nos, então, enquanto pesquisadores, questionar: Se tal método não corresponde às expectativas para uma boa formação da consciência linguística nos alunos do Ensino Médio, qual deveria, então, ser a perspectiva metodológica que garantiria um bom processo de ensinoaprendizagem de Língua Portuguesa atualmente? O que dizem, a respeito disso, os documentos oficiais que regem a legislação da educação brasileira?

Frente a esses questionamentos incitadores, pretendemos - com esta investigação - avaliar as contribuições dadas pela proposta de ensino de gramática contextualizada para o ensino de Língua Portuguesa, destacando-se como um dos documentos oficiais da legislação do Ensino Médio - no caso, as Orientações Curriculares do Estado do Ceará - valorizam-na e divulgam-na entre os profissionais da área.

No intuito de contemplarmos e estruturarmos plenamente as considerações e análise desta pesquisa, este artigo está organizado em unidades retóricas menores a fim de sermos didáticos e objetivos. Após esta introdução, discutimos o ensino de Língua Portuguesa em relação aos seus objetivos e, posteriormente, apresentamos os princípios e as finalidades da gramática contextualizada. Em seguida, apresentamos nossas constatações quanto à visão das Orientações Curriculares do Estado do Ceará sobre o ensino de gramática contextualizada. Por fim, fazemos nossas considerações finais, demonstrando se o objetivo ao qual nos propomos foi alcançado.

\section{DOS OBJETIVOS DO ENSINO DE LÍNGUA MATERNA}

Comecemos por afirmar que um dos papéis da escola é ensinar o aluno a ler e escrever (POSSENTI, 1996. ANTUNES, 2014). Garantir esses dois processos, segundo os autores referenciados, é essencial para que o sujeito adentre, de forma efetiva, na comunidade letrada, e mais que isso, permite-lhes o conhecimento e a leitura de mundo (FREIRE, 1989). Acreditamos que é a partir dessas duas premissas que se dará o acesso a outros saberes de forma sistemática, tais como: os conhecimentos matemáticos, geográficos, históricos etc.

Possenti (1996) é categórico ao afirmar que esse não é, e nem deveria ser, o único objetivo da escola, tampouco das aulas de língua. Mas ele compreende e espera que, a partir dessa perspectiva, o aluno, em seus 
anos finais da educação básica, atinja também outras dimensões, além do saber ler e escrever. Almeja que os alunos sejam capazes de redigir textos em gêneros diversos, atentando-se para a configuração específica do gênero, em consonância com a intenção comunicativa que se pretende alcançar. Que leiam textos diversificados e complexos e saibam se posicionar criticamente. Nesse leque de objetivos secundários, o autor destaca a importância, para esse nível escolar, de o aluno ter acesso aos clássicos da literatura, do nacional ao universal.

Quanto ao papel da leitura e da escrita na escola, Raupp (2005, p. 53) ressalta a importância dessas duas premissas entre os objetivos do ensino de língua "é (ou deveria ser) ensinar o aluno a ser um usuário desenvolto da língua oral e da língua escrita, nas diversas situações de uso e registro". A leitura e a escrita, segundo Raupp (2005), devem ser compreendidas como partes que se integram e que são dependentes entre si, pois é a partir da leitura e do contato com a diversificação de textos escritos que o indivíduo alargará sua capacidade de escrita.

Nesse sentido, o teórico compreende que o objetivo de ensinar língua materna é também capacitar os indivíduos a se reconhecerem como sujeitos da história por meio do uso da palavra e da linguagem. Diante dessas considerações, compreendemos que a leitura e a escrita possuem papel primordial no ensino, pois é através deles que o cidadão é capaz de refletir e argumentar sobre o que o circunda socialmente.

Também visando apontar os principais objetivos do ensino de língua materna, Travaglia (2011) respalda que a escola deve assegurar o desenvolvimento da competência comunicativa dos alunos. Por esse viés, o docente deve capacitar seus alunos, verdadeiros usuários da língua, a utilizar, de forma competente e eficiente, o maior número de recursos que a língua lhes dispõe (morfemas, palavras, orações, frases, textos etc.).

Utilizar tais recursos, de forma competente e hábil, é assegurar que o aluno acioná-los-á e atentar-se-á aos efeitos de sentidos que objetiva alcançar em situações específicas de comunicação. As aulas devem ainda formar cidadãos capazes de produzir e compreender textos, orais ou escritos, que estabeleçam sentido com o mundo à sua volta e estejam correlacionados com o seu contexto sócio-histórico-ideológico.

Travaglia (2011) acredita que, aproveitando o domínio competente que o falante nativo já leva consigo à escola, de pelo menos uma variedade da língua, seja um dos fatores que contribua para o alcance do objetivo de língua materna que é de capacitar os alunos a:
[...] utilizar, de modo adequado, variedades da língua em que eles não têm competência ou tem competência limitada, levando-o a usar adequadamente um maior número de recursos disponíveis na língua para a produção de efeitos de sentido e, consequentemente, para a comunicação competente (TRAVAGLIA 2011 p. 93-94).

Valer-se dessa prática é, portanto, propiciar novas habilidades linguísticas e ampliar os conhecimentos linguísticos que os alunos já possuem da sua própria língua e articulam, de forma exitosa, em situações sociais concretas. Essa prática é conhecida como ensino produtivo (HALLIDAY; MCINTOSH; STREVENS, 1974), uma vez que objetiva desenvolver a competência comunicativa dos alunos.

Em meio a essas discussões acerca do papel do ensino de língua materna, destacamos também o posicionamento teórico de Possenti (1996) e Bagno (2001) segundo, os quais a norma padrão deve estar inclusa nessa lista de objetivos.

Para eles, a escola deve ensinar norma-padrão para garantir que os seus discentes elevem o seu grau de domínio da escrita padrão. Bagno (2001) ressalta que esse ensino não deve ser prioridade, tampouco exclusividade. Possenti (1996) afirma que é partindo da compreensão e do entendimento de que os alunos já chegam à escola com pelo menos uma variedade da língua que a escola deveria, a partir de então, favorecer o aprendizado de uma nova variedade, dita padrão e de maior prestigio socialmente.

O ensino da norma-padrão tem o objetivo de favorecer ao aluno condições de uso dos recursos linguísticos mais aceitos socialmente para serem empregados naquelas situações comunicativas em que há primazia de formalidade e rigoroso monitoramento discursivo (BAGNO, 2001).

Além de defender o ensino da norma padrão na escola, Possenti (1996) argumenta que o professor precisa decidir qual deve ser o tempo proporcional que destinará às estratégias que são contempladas no ensino de língua materna, dentre elas, leitura, redação, gramática etc. No entanto, ele afirma que essa decisão varia conforme o nível de ensino e o tipo de classe e até mesmo o tipo de escola.

Acreditamos que é diante da postura ideológica do docente e da escola que poderemos perceber o que é enfatizado nas aulas de língua materna. Concordamos com Travaglia (2009) que é diante da concepção que o docente tem de linguagem e de gramática que sua prática pedagógica se fundamentará. Por termos tal compreensão, damos ênfase a uma das três concepções de linguagem apresentadas por Travaglia (2009) - a linguagem como processo de interação - a qual acredita- 
mos que deva estar subjacente às práticas de ensino dos professores de Língua Portuguesa.

Segundo o autor, essa acepção faz o indivíduo usar a língua não somente para exteriorizar o pensamento, tampouco para simplesmente transmitir informações a outra pessoa, pois "a linguagem é, um lugar de interação humana, de interação comunicativa pela produção de efeitos de sentido entre os interlocutores, em uma dada situação de comunicação e em um contexto sóciohistórico e ideológico" (TRAVAGLIA, 2009, p. 23).

Nessa perspectiva, a linguagem deve ser considerada como forma de o indivíduo agir, atuar, realizar ações diversas, estando ela inseparável da dimensão social, histórica, humana e dialética, nas quais o sujeito está inserido. O indivíduo é, portanto, considerado em sua ação coletiva, a qual se configura nas condições de produção do enunciado ou do discurso no processo interlocutivo. (TRAVAGLIA, 2002 apud CAMPOS, s/d).

\section{GRAMÁTICA CONTEXTUALIZADA: PRINCÍ- PIO E FINALIDADES}

Antunes (2014) pontua a tentativa pouco exitosa da escola ao tentar trabalhar com a gramática contextualizada. Ressalta que, no meio pedagógico, é comum a insistência, por parte de docentes, em pautar o ensino gramatical em textos reais e concretos. Isso, segundo a autora, acontece desde as recomendações institucionais do Ministério da Educação, que, em seu documento oficial, os Parâmetros Curriculares Nacionais (PCNs), tem recomendado a prática de contextualizar os conteúdos didáticos das disciplinas do ensino básico. Essas recomendações naturalmente estendem-se à Língua Portuguesa.

O que percebemos é que as recomendações são "impostas" àqueles profissionais que trabalham com a língua(gem). Essa imposição se dá pela sua falta de preparação em trabalhar, de forma didática e eficaz, o que lhes é orientado pelo documento oficial. A teoria dos documentos direciona à gramática contextualizada, mas, na prática, não é o que tem acontecido (ANTUNES, 2014).

A falta de preparo destes profissionais se desencadeou em uma tentativa "disfarçada" em abordar os conteúdos gramaticais de forma contextualizada. O texto passou a fazer parte da abordagem de ensino; no entanto, o que fazer com ele? Além desta indagação, outra: o que seria feito com as velhas práticas de ensino da gramática tradicional? É diante desses questionamentos que entendemos que a "imposição" dos documentos oficiais não se validou na prática da sala de aula, pois, mesmo com os avançados estudos da Pragmática e da
Semântica sendo recomendados pelos PCNs, não foram concedidos espaços fecundos a essas áreas de estudo.

É certo que os documentos oficiais, desde 1996, têm tentado se reestruturar e acompanhar os avanços da linguística moderna. Têm se proposto a orientar os estudos linguísticos na sala de aula, de forma que esses estejam organizados e baseados no funcionamento interativo da linguagem, o que implica dizer que é no texto real e concreto que se dá a proposta e o objeto de ensino da sala de aula. Todavia, Antunes (2014) salienta que, com essas novas propostas, tem ocorrido resistência por parte daqueles que estavam habituados a ministrar aulas descontextualizadas pautadas em análise linguística, "com foco nos elementos estruturais de composição dessas frases, do fonológico ao sintático" (2014, p. 41).

O que se tem percebido, efetivamente, é a conciliação entre os métodos tradicionais com as novas orientações, resultando na junção de "texto" e "gramática", o que, na visão de Antunes, "chamou-se [...] de 'gramática contextualizada', que na verdade, de texto e gramática tinha muito pouco" (2014, p. 42, grifo do autor). Tal conciliação, Lajolo (1986 apud ANTUNES, 2014 , p. 42) foi um "pretexto" para se fazer o que estava sendo orientado sem deixar as antigas práticas.

A solução encontrada em juntar texto e gramática consistia, na realidade, em recorrer ao texto, com toda sua riqueza multimodal, para retirar frases (com o objetivo de se fazer análises sintáticas) e palavras (com a finalidade de se desenvolver análises fonológicas e morfológicas), sem levar em consideração seus contextos e suas funcionalidades dentro do próprio texto. Essa perspectiva metodológica de se fazer gramática contextualizada, leva-nos a compreender que os fatores contextuais não lhes são essenciais e indissociáveis, mas "uma opção metodológica", conforme afirma Antunes (2014). Passemos a compreender, agora, quais são as características e finalidades da perspectiva pautada na contextualização do ensino de gramática baseando-se alguns autores que têm discutido o ensino de Língua Portuguesa no Brasil, dando maio ênfase a discussão empreendida por Antunes (2014) que, como já dito, é uma das maiores referências, no Brasil, quanto à defesa do ensino contextualizado de gramática.

Ao entendermos que "toda atividade com a linguagem é irremediavelmente contextualizada" (ANTUNES, 2014, p. 109), conseguimos perceber a incongruência pedagógica com que vem sendo trabalhada a linguagem e a gramática em algumas instituições escolares que não os têm relacionados.

Ratificamos que não há comunicação, seja ela es- 
crita ou falada, sem um contexto social que influencie nas escolhas feitas pelo próprio falante na construção textual. Não há comunicação sem interação entre, no mínimo, dois interlocutores no ato comunicativo. Então, não há por que fazer, em sala de aula, análises e mais análises de frases e palavras soltas, sem levar em consideração seus fatores extralinguísticos.

Antunes (2014) elucida que o rótulo "contextualizado" é redundante, tanto para a linguagem quanto para a concepção de gramática, uma vez que ambos são inerentes ao contexto. Não se pode compreender a gramática e a linguagem fora da atividade verbal, pois toda atuação verbal acontece inserida em uma dada situação social. Porém, isso não implica dizer que é só adicionar à linguagem e à gramática um contexto que os tornamos contextualizados, não se trata disso. Tal atitude levaria a afirmar que a linguagem, a gramática e o contexto são elementos distintos, ficando à escolha do falante sua mistura ou não.

Diante dessa concepção errônea, a teórica destaca que, na interação verbal, "o próprio contexto é um elemento constitutivo dos sentidos expressos, e assim, a linguagem não é algo que existe "fora de contexto", ajuntado a ele de fora para dentro, como algo adicional ou apenas acrescentado" (ANTUNES, 2014, p. 40).

É pelo entendimento de que não há língua sem participantes e sem intenções comunicativas que se justifica a necessidade de um ensino de gramática contextualizada. Destacamos, ainda, que, por ser essencialmente contextualizada, a proposta desse ensino é "apenas uma estratégia metodológica...” (ANTUNES, 2014, p. 110), que pretende fazer dos usos reais do texto o seu objeto de ensino-aprendizagem.

Marcuschi (1997) pontua que o trabalho com o ensino de língua é dependente dessas opções pedagógicas e ideológicas do professor. Nesse sentido, deixamos claro que a concepção de linguagem compreendida pela gramática contextualizada trata-se da linguagem enquanto interação social a qual discutimos anteriormente e que, segundo Koch (2006, p. 26), considerase, nessa acepção, "os sujeitos como atores / construtores sociais, sujeitos ativos que - dialogicamente constroem-se e são construídos no texto, considerado o próprio lugar da interação e da constituição dos sujeitos da linguagem". Apoiada por essa base conceitual, a gramática passa a ser compreendida como um dos componentes de que se constitui um sistema linguístico.

Essas mudanças não acontecem por acaso e nem são criadas "fora" da ação de seus falantes, mas sim com a contribuição de cada um deles. Com isso compreendemos que "não existe uma gramática fora da língua", conforme concebe a gramática normativa. O processo interativo das ações verbais muito contribui para que se consolide a concepção de gramática internalizada. Logo, é nesse processo de internalizar as "normas" linguísticas que se constitui o saber linguístico de todo falante (TRAVAGLIA, 2009).

Por fim, Antunes (2014, p. 18) considera o conceito de interação como uma ação entre dois ou mais sujeitos, como uma ação conjunta, recíproca e a linguagem como: "fazer um agir de um com outro, de um para outro, no sentido de que a finalidade última do que é dito é gerar uma resposta no outro".

A proposta do ensino de gramática contextualizada é também fornecer aos alunos as "possibilidades linguísticas" que lhes são ofertadas por meio do sistema linguístico. Segundo Antunes (2014), para que o ensino de gramática aconteça numa perspectiva contextualizada, é necessário atender a algumas "finalidades específicas". Dessa maneira, cabe principalmente ao sujeito condutor do ensino saber contextualizar o que se normatiza, tendo em vista quatro finalidades específicas apontadas pela autora as quais passamos a comentar a seguir.

\subsection{Especificar Oralidade E Escrita}

Esta finalidade consiste em explicitar aos discentes se a norma gramatical equivale à escrita ou à fala, deixando claro que existe distinção entre ambos, apesar de não serem contraditórios e nem "dicotômicos ou inteiramente autônomos entre si". É preciso ter cuidado para, no momento da abordagem, não alimentar a concepção de que estudar a oralidade é irrelevante, pela falsa justificativa de que todos já sabemos falar, dandolhe menor importância dentro dos estudos linguísticos. Outra ideia errônea é acreditar que a fala é caótica e, por isso, não há necessidade de estudá-la.

Marcuschi (1997) também entende que não há contradição entre oralidade e escrita, mas sim uma "postura" pedagógica do docente que enfatiza uma em detrimento da outra. Desse modo, os que dão maior credibilidade à escrita não dão ao aluno a oportunidade de perceber as manifestações possíveis da língua na sua modalidade oral, mesmo a fala sendo uma prática mais comum do que a escrita no cotidiano dos alunos. É dessa forma que a escola percorre o caminho inverso, pois prefere partir do menos habitual a iniciar pelo que é mais usual para o seu público-alvo. 


\subsection{Especificar O Nível De Formalidade: Formal Ou Informal}

Esta segunda finalidade atenta-se para a importância que é dada tanto às normas gramaticais quanto aos seus níveis de formalidade. Tal prática alimenta a concepção de que a língua é, por excelência, contextualizada, uma vez que não se escreve sem uma intenção e sem destinála a nenhum sujeito. A escolha feita pelo falante, ao selecionar seu destinatário e a sua finalidade comunicativa, implica em fazer opção de um desses níveis, porque, dependendo do sujeito a quem se destina o texto oral ou escrito e da situação de produção, o falante pode recorrer ao intermediário entre os níveis. Isso consiste dizer que ele pode escolher do mais ao menos formal, ou, do mais ao menos informal. Essa escolha se dará justamente pelo próprio falante que analisa o contexto e entende que há flexibilidade entre a distinção formal $\mathrm{x}$ informal, não havendo, portanto, a rigidez de apenas um nível dentro do texto.

A autora ressalta, ainda, o cuidado com outra concepção distorcida: a informalidade é característica única da fala, e a formalidade é típica somente da escrita, como se ambas fossem inflexíveis e não pudesse haver inversão. A depender da situação comunicativa, o falante pode sim fazer uso de uma escrita informal, desde que sua intenção comunicativa lhe solicite isso, como é o caso de conversas virtuais, bilhetes etc. Da mesma forma acontece com a fala, pois se for uma situação de um seminário, palestra, entrevista de emprego, por exemplo, o falante possivelmente recorrerá à formalidade para atender seus objetivos comunicativos.

\subsection{Especificar Se Trata De Padrões Fixos}

Nesta especificidade, a autora destaca a relevância de explorar as possibilidades de que o falante dispõe no sistema de sua língua, visto que:

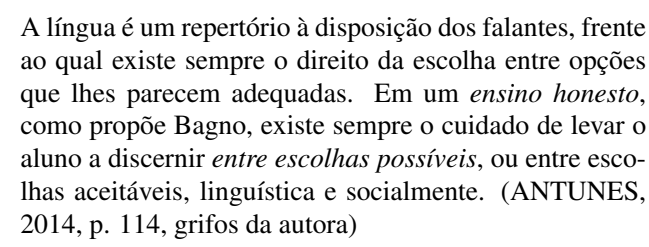
ao qual existe sempre o direito da escolha entre opções que lhes parecem adequadas. Em um ensino honesto, como propõe Bagno, existe sempre o cuidado de levar o aluno a discernir entre escolhas possiveis, ou entre escolhas aceitáveis, linguística e socialmente. (ANTUNES, 2014, p. 114, grifos da autora)

Para exemplificar, podemos citar situações interativas em que o interlocutor possui a opção de escolher entre a construção "a maioria das pessoas é" ou "a maioria das pessoas são", cabendo somente a ele selecionar uma dessas expressões. Lembremos que essa preferência se dará diante de uma motivação, e nunca de forma aleatória.
Por outro lado, dentro da configuração estrutural da língua, há casos em que essas escolhas não são possíveis, pois só há uma opção linguística a ser utilizada no ato comunicativo, o que a autora denomina de "padrões fixos", como é no caso do emprego do artigo que obrigatoriamente deve ser posto antes do substantivo, do pronome "lhe" - que não deve funcionar como sujeito, a citar alguns.

\subsection{Especificar Se A Abordagem É Descritiva Ou De Natureza Normativa}

A finalidade desta especificidade se deve à necessidade de professores saberem direcionar a que contextos reais a abordagem de determinado conteúdo da gramática se aplica no mundo real, já que é no uso que a norma se efetiva. É necessário que o aluno compreenda se a abordagem gramatical feita pelo professor se aplica a contextos nos quais se deve usar a norma-padrão ou a usos em que não há necessidade de monitoramento da língua. Portanto, o professor tem de ter consciência da abordagem que utiliza para que o aluno compreenda e saiba aplicar em seu cotidiano.

Nessa mesma dimensão, o professor tem de especificar que existem questões na língua, e até mesmo na própria gramática, que não são consensuais entre os gramáticos. Isso não quer dizer que a língua seja aleatória, tampouco desordenada, mas dinâmica e sujeita a mudanças.

Analisar a que público se destina a abordagem linguística também se faz necessário, pois "são sujeitos distintos, com capacidades cognitivas e com interesses mais imediatos também distintos" (ANTUNES, 2014, p. 57). Verificar qual é o conceito que se tem por trás das explanações conceituais e dos exercícios empregados nos livros didáticos é de suma importância, pois essa análise ajuda o professor a perceber quais são as concepções propagadas pelos autores acerca do que é língua(gem) e gramática. Essa prática contribui na prática pedagógica do docente, uma vez que o livro, normalmente, é a base para a sua prática de ensino.

Concordamos com Antunes (2014) que, se o profissional atentar para essas quatro "finalidades específicas", o ensino da gramática apresentará maior êxito e será de melhor compreensão para os discentes, haja vista que a abordagem se pautará na contextualização de todo conteúdo, dando ao aluno a chance de estabelecer a correspondência entre aquilo que aprende na escola e as vivências sociais que experiência. Toda essa situação se justifica pelo mesmo entendimento de Antunes (2014), segundo a qual "qualquer questão gramatical somente se define no âmbito das práticas sociais 
de uso da linguagem, que, por sua vez, é refém da atividade textual." Relegar a segundo plano a prática da produção e avaliação do texto no ensino de língua é, no mínimo, retirar sua essência e desmerecer toda sua conjuntura de elementos contextuais, pois são eles que fazem os elementos gramaticais terem sentido no próprio texto.

\section{METODOLOGIA}

Em termos metodológicos, esta pesquisa, motivada a saber quais são os pressupostos teórico-metodológicos do ensino de gramática numa perspectiva contextualizada e, ainda, o que as Orientações Curriculares do Estado do Ceará dizem a respeito, foi realizada em duas etapas.

Inicialmente, a fim de garantirmos eficientemente os objetivos aos quais esta pesquisa se empreendeu, fizemos um levantamento teórico para que pudéssemos compreender melhor o que alguns autores afirmam sobre o ensino de língua materna e quais seus objetivos enquanto disciplina que percorre toda trajetória escolar dos sujeitos. Para tal, recorremos às considerações de Possenti (1996), Bagno (2001), Raupp (2005), Waal (2009), Travaglia (2009), Travaglia (2011), entre outros. Além desse aporte teórico, ancoramo-nos também principalmente nos pressupostos de Antunes (2014), uma das pesquisadoras que mais têm se disposto a mostrar as eficácias do ensino contextualizado de gramática no Brasil. Essa primeira etapa se caracteriza como bibliográfica, segundo Marconi e Lakatos (2003), porque recorremos a fontes secundárias, tais como teses, pesquisas, monografias etc., para nos aprofundarmos no assunto.

Ainda conforme Marconi e Lakatos (2003), a segunda etapa aproxima-se de uma pesquisa documental, porque nos reportamos a um documento de utilidade pública para fazermos uma análise que visava averiguar se a legislação vigente no Ensino Médio apresenta orientações curriculares sobre como deve ser o ensino de gramática nesse nível da Educação Básica. Desse modo, analisamos as Orientações Curriculares do Estado do Ceará que é um documento resultante de um trabalho coletivo de técnicos e de professores da rede estadual do Ceará que objetivavam produzir um material que auxiliasse os docentes da rede nas grandes áreas curriculares: Linguagens, Códigos e suas Tecnologias; Ciências da Natureza; Matemática e suas Tecnologias e Ciências Humanas e suas Tecnologias.

Disponibilizada pela Secretaria de Educação do Estado do Ceará (SEDUC) aos professores do Ensino Médio, a coletânea "Escola Aprendente" apresenta orienta- ções curriculares pautada nos princípios da contextualização e da interdisciplinaridade. A coleção apresenta quatro volumes, no entanto nossa análise consiste no volume II, o qual abrange a área da Linguagem e Códigos, com ênfase na disciplina de Língua Portuguesa.

\section{RESULTADOS DA ANÁLISE REALIZADA NO DOCUMENTO "ORIENTAÇÕES CURRI- CULARES DO ESTADO DO CEARÁ"}

Inicialmente, o documento salienta a importância dessa disciplina para o aluno do Ensino Médio, a qual é pautada em competência/habilidade de conteúdos que contribuem na formação de um sujeito participativo, reflexivo e protagonista. Sinaliza que esses objetivos não serão alcançados com atividades mecânicas, tampouco com o tradicionalismo do ensino que parte das regras gramaticais para o uso das práticas sociais. Será alcançado a partir da perspectiva de que o estudo de língua materna vai além de abordagens gramaticais, o qual parte do uso das práticas sociais para só depois sistematizar as categorias gramaticais da língua.

O que se espera das aulas de Língua Portuguesa, atualmente, é que esta seja capaz de articular o processo de ensino e aprendizagem da leitura (compreensão e interpretação), da produção textual, dos aspectos textuais e da análise e reflexão. Seja, também, criativa e participativa no sentido de além de, desenvolver a competência de produzir textos reais e escritos nos alunos, garanta também a leitura e interpretação de textos escritos na língua materna.

Percebemos, durante a análise, a clareza e objetividade desse documento em afirmar ao seu público-alvo os objetivos do ensino de língua e que perfil de aluno se pretende construir a partir dessas escolhas metodológicas. Quanto aos pressupostos teóricos que embasam o documento, percebemos com mais clareza no seguinte trecho:

\footnotetext{
A considerar este espectro, o ensino de Língua Portuguesa deve estar alicerçado nos pressupostos da Lingüística Textual, privilegiando uma concepção dialógica de linguagem centrada em textos, como unidade básica de ensino da língua. Deve enfocar a existência de diferentes gêneros e tipos textuais em circulação na sociedade, determinados em função das intenções comunicativas e de seus usos sociais, quer sejam escritos ou orais, levando o aluno a interpretar e produzir significados através da reflexão (CEARÁ 2008 p. 10).
}

Constatamos que as orientações estaduais, diferentemente de outros documentos como os PCN, possuem maior embasamento, pois menciona, entre outras, as contribuições da teoria dos gêneros textuais proposta 
por Bakhtin (1997), os quais têm surtido efeitos positivos quando, no âmbito da sala de aula, os professores baseiam-se nessa perspectiva da diversidade de gêneros textuais. Essa afirmação é do próprio documento que incita o ensino dos gêneros textuais em sala, uma vez que, entre outros pontos positivos, amplia e diversifica a capacidade dos alunos de produzir textos orais e escritos, como também “[...] aprimora a sua capacidade de recepção com base nos diferentes gêneros de leitura/ audição, produção, compreensão e interpretação dos textos". (CEARÁ, 2008, p. 10)

A defesa dos gêneros textuais se justifica, também, porque ele é um instrumental que possibilita ao indivíduo ampliar os conhecimentos de sua língua e o faz compreender como se constitui a linguagem em suas práticas sociais concretas, sejam elas em modalidades textuais orais ou escritas. Além disso, essa metodologia de ensino e aprendizagem da língua confirma, nos alunos, sua autonomia de produzir textos reais e concretos, aos quais eles recorrerão em determinada situação social. Dessa forma, "a escola passa a ser uma oficina de textos de circulação social, um local onde deve ser viabilizado a adoção de estratégias de trabalhos com gêneros..." (CEARÁ, 2008, p. 11).

\section{Evidências escritas provam que a escolha do gênero não pode deixar de levar em conta parâmetros essenciais, como: quem está falando, para quem está falando, qual a sua finalidade e qual o assunto a ser tratado, considerados para Bakhtin (1997) como imprescindíveis. Segundo este autor, todos os textos que produzimos apre- sentam um conjunto de características "relativamente es- táveis", tenhamos ou não consciência dessas. São, por- tanto, tais características que configuram os diferentes gêneros e tipos textuais. (op. cit, 2008, p. 11, grifo do autor)}

Essas práticas com a diversidade dos gêneros, vivenciadas na própria escola, confirma o rompimento do ensino tradicional de fixação de regras exaustivas, descontextualizadas de situações reais de uso e se efetiva na proposta dos documentos analisados: ofertar um ensino de língua que proporciona ao aluno produção de textos reais e concretos, atentando-se aos propósitos comunicativos. Por esse viés, a disciplina pauta-se numa perspectiva sociointeracionista, que assegura, enfim, "que a sala de aula seja considerada como espaço de interlocução, em que cada sujeito tenha o livre arbítrio de expressar a palavra e que esta encontre ressonância no discurso do outro." (CEARÁ, 2008, p. 11-12).

Ao considerar o texto como objeto do ensino de língua, o documento apresenta sugestões metodológicas ancoradas em competências que sinalizam o perfil do aluno que se pretende formar nos anos finais da Edu- cação Básica. Entre essas competências, elencamos algumas, as quais mais se aproximam da proposta pedagógica que temos defendido: a garantia do ensino de gramática contextualizada:

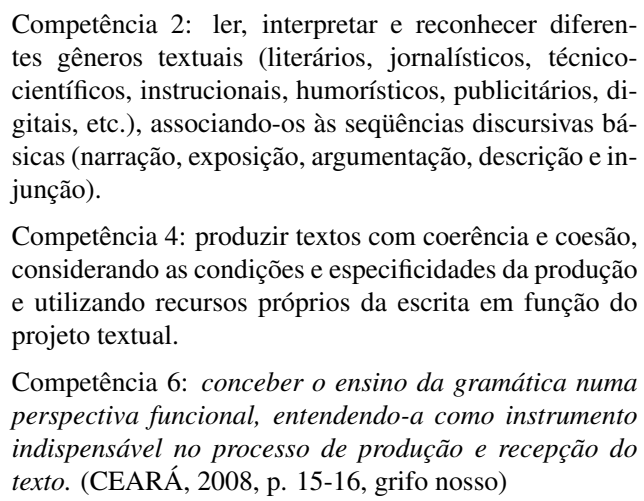
científicos, instrucionais, humorísticos, publicitários, digitais, etc.), associando-os às seqüências discursivas básicas (narração, exposição, argumentação, descrição e injunção).

Competência 4: produzir textos com coerência e coesão, considerando as condições e especificidades da produção e utilizando recursos próprios da escrita em função do projeto textual.

Competência 6: conceber o ensino da gramática numa perspectiva funcional, entendendo-a como instrumento indispensável no processo de produção e recepção do texto. (CEARÁ, 2008, p. 15-16, grifo nosso)

Os gêneros textuais é, por excelência, como temos enfatizado, o material essencial do professor de Língua Portuguesa no ensino Médio que, orientado pela coletânea, deve trabalhar a diversidade dos gêneros em situações formas e informais de comunicação, confirmando, para o aluno, que toda situação sociocomunicativa se constitui nos parâmetros de algum gênero textual.

Nesse sentido, o documento é enfático ao apresentar os pontos benéficos dessa proposta de ensino baseado na noção de gênero, pois só assim o ensino de língua assume seu caráter pedagógico de permitir os alunos serem produtores e receptores de textos orais e escritos que atendem aos seus propósitos comunicativos.

É nessa perspectiva que o ensino de gramática se consolida: nos usos reais e concretos dos textos. Com essa afirmativa, o documento reforça que esses conhecimentos da estrutura linguística são imprescindíveis no processo e recepção do texto, validando-os de uma vez por toda, desde que se considerem os gêneros textuais.

A proposta de ensino em questão, segundo a coletânea, evita o trabalho descontextualizado das categorias gramaticais, uma vez que, no texto, o aluno perceberá a funcionalidade de tais regras, as quais serão definidas de acordo com a especificidade de cada gênero. Acusa, ainda, a avaliação negativa que a escola oferece aos seus alunos ao alimentar o mito de que existe uma forma "correta" de falar, o que dissemina ainda mais o preconceito linguístico. O documento enfatiza também que o papel do ensino de língua é ofertar aos alunos as escolhas possíveis de formas diversas de se expressar na oralidade, considerando seus contextos de uso e adequando-as à situação comunicativa.

Por fim, a coletânea confirma sua proposta para o ensino de Língua Portuguesa: "Diante disso, sugerimos 

ESTADO DO CEARÁ

um trabalho em sala de aula, que leve em conta a função e o uso da linguagem de forma a oferecer um ensino contextualizado, partindo do contexto sociocultural do aluno valorizando a sua identidade e a sua comunidade discursiva." (CEARÁ, 2008, p. 19). Percebemos, com essa citação, o diálogo explícito das orientações curriculares do Ceará com a proposta teórico-metodológica que temos defendido nesta pesquisa.

\section{CONSIDERAÇÕES FINAIS}

Nesta pesquisa, evidenciamos a proposta da gramática contextualizada no ensino de Língua Portuguesa, pontuando algumas discussões teóricas, sobretudo as empreendidas por Antunes (2014) que tem sido, no Brasil, uma das autoras que mais tem defendido, enfaticamente, essa perspectiva. Em suma, discutimos que, na prática, para ensinar Língua Portuguesa na perspectiva contextualizada, é imprescindível a presença do texto, pois, embora o foco seja explorar um aspecto gramatical da língua, esta não pode se desvincular dos sentidos e intenções subjacentes à construção textual. O estudo de elementos gramaticais só se justifica no e pelo uso, uma vez que ela é "serva" dos sentidos e intenções que queremos expressar, os quais estão materializados nos textos, sejam eles orais ou escritos.

Vimos que a proposta do ensino contextualizado de gramática abrange muito mais elementos, pois é necessário consolidar todo um conjunto de fatores contextuais que envolvem o cenário de interação da língua, sejam eles linguísticos ou não (ANTUNES, 2014). No entanto, deixemos claro que, mesmo reconhecendo essa gama de fatores a serem levados em consideração, esta pesquisa não pretendeu explorá-los à exaustão, ou seja, ainda há outras discussões acerca do assunto como, por exemplo, investigar a prática dessa perspectiva no âmbito da sala de aula.

Após discutirmos os princípios e finalidades dessa proposta de ensino que ressalta a importância pragmática da interação verbal, dos elementos gramaticais justificados no texto e pelo texto, realizamos uma análise minuciosa para averiguarmos se e como o documento "Orientações Curriculares do Estado do Ceará" tem orientado algo nesse sentido aos professores de Língua Portuguesa do estado a respeito do assunto no contexto do Ensino Médio.

Em linhas gerais, constatamos que as Orientações Curriculares do Ceará é um documento objetivo, no sentido, de explicitar, com ênfase, que a base do ensino de Língua Portuguesa deve ser, inevitavelmente, a diversidade de textos que circulam no meio social.
Constatamos que o documento desconsidera, veementemente, o ensino tradicional de Língua Portuguesa centralizado em análises isoladas da estrutura da língua, valendo-se do texto como "pretexto". As orientações curriculares do estado confirmam, inclusive, o que temos proposto nessa pesquisa: que o ensino de Língua Portuguesa deve ser contextualizado considerando as categorias gramaticais com sua função aplicada no texto, pois é nas práticas sociais que estas se efetivam.

A análise realizada no documento vigente para o Ensino Médio do Estado do Ceará apresenta, didaticamente, como deve se suceder o ensino de língua nos anos finais da educação básica. Consideramos relevante que documentos dessa natureza apresentem uma linguagem mais acessível, a fim de que os docentes que os lerem possam compreendê-los de forma mais clara e, assim, tenham facilidade para aplicar suas orientações na sala de aula.

Dessa forma, as considerações do documento analisado compreende que o ensino de Língua Portuguesa, no Ensino Médio, deve contemplar outras dimensões da língua, além da muito explorada dimensão metalinguística, a qual nos tem apresentado, por séculos, o ensino tradicional. Nesse sentido, os resultados da análise do documento mostram que o objetivo da disciplina de Língua Portuguesa no Ensino Médio é alargar os conhecimentos linguísticos dos alunos, favorecer uma formação crítica a partir de conhecimentos da própria língua, valorizando os conhecimentos gramaticais já internalizados pelos estudantes e formando-os como leitores assíduos, capazes de interpretar - de modo pleno - as potencialidades dos códigos linguísticos, entre outros, tal qual discutido na fundamentação teórica desta pesquisa.

\section{REFERÊNCIAS}

ANTUNES, I. Gramática Contextualizada:

limpando 'o pó das ideias simples'. 1. ed. São Paulo: Parábola Editorial, 2014.

BAGNO, M. Preconceito linguístico: o que é, como se faz. 54. ed. São Paulo: Loyola, 2001.

BAKHTIN, M. Os gêneros do discurso (1952-1953). In: PEREIRA., T. M. E. G. G. e (Ed.). Estética da criação verbal. São Paulo: Martins Fontes, 1997.

BRASIL. Parâmetros Curriculares Nacionais: $3^{\circ}$ e $4^{0}$ ciclos do Ensino Fundamental: Língua Portuguesa. Brasília/DF, 2008.

CAMPOS, E. d. Reflexões sobre o ensino

de gramática. 2016. Disponível em: <http: 
//www.diaadiaeducacao.pr.gov.br/portals/pde/arquivos/

1155-4.pdf>. Acesso em: 15 ago. 2016.

CEARÁ, S. D. E. d. Metodologias de Apoio: áreas de linguagens, códigos e suas tecnologias. Coleção Escola Aprendente. 1. ed. Fortaleza: SEDUC, 2008. v. 2.

FREIRE, P. A importância do ato de ler: em três artigos que se completam. 1. ed. São Paulo: Cortez, 1989. Coleção polêmicas do nosso tempo; 4.

HALLIDAY, M. A. K.; MCINTOSH, A.; STREVENS, P. As ciencias linguisticas eo ensino de linguas. 1. ed. Petrópolis: Vozes, 1974.

KOCH, I. G. V. Ler e compreender: os sentidos do texto. 1. ed. São Paulo: Contexto, 2006.

MARCONI, M. A.; LAKATOS, E. M. Fundamentos de metodologia científica. 5. ed. São Paulo: Atlas, 2003.

MARCUSCHI, L. A. Concepção de língua falada nos manuais de português de $\mathbf{1}^{\circ}$. e $\mathbf{2}^{\circ}$. Graus: uma visão crítica. [S.1.]: Trabalhos em Lingüística Aplicada, 1997.

POSSENTI, S. Por que (não) ensinar gramática na escola. 1. ed. Campinas: Mercado das Letras, 1996.

RAUPP, E. S. Ensino de língua portuguesa: uma perspectiva lingüística. Publicatio UEPG: Ciências Humanas, Linguistica, Letras e Artes, v. 13, n. 2, p. 49-58, 2005.

TRAVAGLIA, L. C. Gramática e interação: uma proposta para o ensino de gramática. 14 . ed. São Paulo: Cortez, 2009.

Gramática ensino plural. 1. ed. São Paulo: Cortez, 2011.

WAAL, D. V. D. Gramática e o ensino da língua portuguesa. In: IX Congresso Nacional de Educação. III Encontro sul Brasileiro de psicopedagogia. PUCPR: PUCPR, 2009. p. 983-994. 